\title{
Spontaneous Spinal Epidural Hematoma : A Surgical Case Series of Ten Patients
}

\section{Raj, Rahul}

2016-09

Raj , R , Seppala , M \& Siironen , J 2016 , ' Spontaneous Spinal Epidural Hematoma : A

Surgical Case Series of Ten Patients ' , World Neurosurgery , vol. 93 , pp. 55-59 . https://doi.org/10.1016/j.wneu.201

http://hdl.handle.net/10138/231309

https://doi.org/10.1016/j.wneu.2016.05.072

publishedVersion

Downloaded from Helda, University of Helsinki institutional repository.

This is an electronic reprint of the original article.

This reprint may differ from the original in pagination and typographic detail.

Please cite the original version. 


\title{
Spontaneous Spinal Epidural Hematoma: A Surgical Case Series of Ten Patients
}

\author{
Rahul Raj, Matti Seppälä, Jari Siironen
}

BACKGROUND: Spontaneous spinal epidural hematoma (SS-EDH) is a rare neurosurgical emergency. Little is known about predictive factors of outcome in patients with SS-EDH. Here, we present a case series of patients operated on for an SS-EDH.

METHODS: We reviewed all cases of patients operated on for an SS-EDH between January 2009 and February 2016 in a large academic neurosurgical center. We recorded preadmission functional status, bleeding characteristics, and postsurgery outcome. Good outcome was defined, according to the Nurick score, as at least being able to walk in a way that did not prevent employment. Mean follow-up time was 19 months (standard deviation, 25 months).

RESULTS: Ten patients, with a mean age of 70 years (standard deviation, 10), with SS-EDH were included. The location of SS-EDH was binomially distributed, with the highest frequencies in the upper thoracic region (Th3-5) and middle to low cervical region (C4-6). Five patients had a poor outcome. Of these, 3 remained chair bound or bedridden. No statistically significant association could be found between preoperative characteristics and outcome, but patients with poor preoperative motor function, thoracic hematoma, and more than 4 involved segments had a high rate of poor neurologic outcome. We could not establish any association between time delay from symptom onset to surgery and outcome.

CONCLUSIONS: In our series, half of the patients with SS-EDH recovered well after surgery. Although no statistically significant association could be established, hematoma location, size, and preoperative motor function seem to be some of the most important predictive factors of postoperative recovery.

\footnotetext{
Key words

- Spinal surgery

- Spontaneous spinal epidural hematoma
}

\section{Abbreviations and Acronyms}

IQR: Interquartile range

SS-EDH: Spontaneous spinal epidural hematoma

\section{INTRODUCTION}

pontaneous spinal epidural hematoma (SS-EDH) is a rare neurosurgical condition with potentially devastating consequences. The incidence of SS-EDH is around o.I/ Iоo,ooo. ${ }^{\mathrm{I}}$ The symptoms may mimic those of cerebral infarction or spinal cord infarction, which makes the clinical diagnosis even more challenging. ${ }^{\mathrm{I}, 2}$

Little is known about risk factors for SS-EDH but higher age and the use of anticoagulants may increase the risk. ${ }^{3}$ Still, most patients with SS-EDH are relatively young (in their 50 ) and not on anticoagulants. ${ }^{4}$

The source of bleeding is believed to be the posterior internal vertebral venous plexus, a structure that is more prominent in adults than in children. ${ }^{5,6}$ The most common locations for SS$\mathrm{EDH}$ are in the middle to lower cervical region $\left(\mathrm{C}_{4}\right.$-ThI) and the lower thoracic upper lumbar region (Thg-LI). ${ }^{4}$

Because of the rarity of SS-EDH, diagnosis is often delayed. Delay of surgical intervention is probably the most important modifiable prognostic factor for recovery after SS-EDH, although little hard evidence has been presented. The strongest prognostic risk factor associated with outcome is preoperative neurologic status, which tightly correlates with operative delay. ${ }^{4}$ Yet, little is known about predictive factors of outcome in patients with SS-EDH. Here, we analyze ro patients operated on for an SS-EDH in our institution from 2009 to early 2016.

\section{METHODS}

Setting

Our institution is one of the largest academic neurosurgical departments in Scandinavia (Töölö Hospital, Helsinki University Hospital, Helsinki, Finland) with a catchment of nearly 2 million people. Approximately 3500 neurosurgical operations are performed here annually.

Patients

From the hospital's electronic surgical registry, we identified all patients operated on for a spinal hematoma. We then manually

Department of Neurosurgery, University of Helsinki and Helsinki University Hospital, Helsinki, Finland

To whom correspondence should be addressed: Rahul Raj, M.D., Ph.D.

[E-mail: rahul.raj@hus.fi]

Citation: World Neurosurg. (2016) 93:55-59.

http://dx.doi.org/10.1016/j.wneu.2016.05.072

Journal homepage: www.WORLDNEUROSURGERY.org

Available online: www.sciencedirect.com

1878-8750/\$ - see front matter (c) 2016 Elsevier Inc. All rights reserved. 
went through the patient charts to exclude all patients with an identifiable cause of bleeding (trauma, after surgery, after lumbar puncture) and included only patients with SS-EDHs. The study was approved by the ethics board of Helsinki University Hospital (I02/13/03/02/2016 TMK02 §73).

We recorded preadmission functional status, bleeding characteristics, and postsurgery outcome. Preoperative neurologic status was defined according to the Frankel classification:

\section{A: Absent motor and sensory function}

B: Sensation present, absent motor function

C: Sensation present, motor function present but not useful (motor strength grade $2-3 / 5$ )

D: Sensation present, motor function present and useful (motor strength grade $4 / 5)$

E: Normal motor and sensory function

Postoperative neurologic status was classified according to the Nurick functional scale grade ${ }^{7,8}$

o: signs and symptoms of root involvement but without evidence of spinal cord disease

I: signs of spinal cord disease but no difficulty walking

2: slight difficulty walking that does not prevent full-time employment

3: extreme difficulty in walking that requires assistance and prevents full-time employment and occupation

4: able to walk only with someone else's help or with the aid of a walker.

5: chair bound or bedridden.
For the univariate outcome analyses, the Nurick score was dichotomized to good outcome $(0-2)$ or poor outcome $(3-5)$, and the Frankel class was dichotomized to poor preoperative function $(A-C)$ or good preoperative function (D and $E)$. The neurologic assessments before and after surgery were made by the treating neurosurgeon. Mean follow-up time was ig months (standard deviation, 25 months).

\section{Statistical Analysis}

Given the small sample size, we used only descriptive statistics. Categorical univariate variables were tested using the Fisher exact test. Continuous normally distributed data were tested using the Student $t$ test, and skewed continuous data were tested using the Mann-Whitney $U$ test. Categorical data are presented as numbers (\%), parametric data as mean (standard deviation), and nonparametric data as median (interquartile range [IQR]). We used SPSS Statistics for Windows, version 2I.o (IBM Corp., Armonk, New York, USA) for the statistical analyses.

\section{RESULTS}

Ten patients were operated on for an SS-EDH between I January 2009 and 2i February 20I6. Individual patient characteristics are shown in Table 1. Patient mean age was 70 years (standard deviation, Io), median age was 68 (IQR, 65-78), and age range was between $5 \mathrm{I}$ and 85 years. Five patients were female. Six patients were on oral anticoagulants (all on warfarin) and 4 patients had no history of oral anticoagulant use. Preoperative admission median international normalized ratio was 3.8 (IQR, $2.4-5.6$ ) in patients on anticoagulants and I.o (IQR, 0.9-I.2) in patients not on anticoagulants. One patient not on anticoagulants (age 69 years) had myelodysplastic syndrome with associated thrombocytopenia (I9 $\times \mathrm{IO}^{9} / \mathrm{L}$ on admission).

Table 1. Individual Patient Characteristics

\begin{tabular}{|c|c|c|c|c|c|c|c|c|c|c|c|}
\hline Patient & $\begin{array}{c}\text { Age } \\
\text { (years) }\end{array}$ & Gender & Hypertension & $\begin{array}{l}\text { Significant } \\
\text { Comorbidity }\end{array}$ & $\begin{array}{l}\text { Antithrombotic } \\
\text { Medication }\end{array}$ & $\begin{array}{c}\text { Admission } \\
\text { International } \\
\text { Normalized Ratio }\end{array}$ & $\begin{array}{l}\text { Time from Symptom } \\
\text { Onset to Admission } \\
\text { (hours) }\end{array}$ & Level & $\begin{array}{l}\text { Frankel } \\
\text { Class }\end{array}$ & $\begin{array}{l}\text { Nurick } \\
\text { Score }\end{array}$ & Death \\
\hline 1 & 45 & M & No & Yes* $^{*}$ & Warfarin & 3.5 & $>48$ & Th3-5 & C & 0 & No \\
\hline 2 & 61 & M & Yes & No & Warfarin & 2.5 & $>48$ & Th3-7 & C & 1 & No \\
\hline 3 & 63 & $\mathrm{~F}$ & Yes & No & No & 1.0 & $<24$ & Th10-L1† & B & 5 & No \\
\hline 4 & 63 & $\mathrm{~F}$ & Yes & No & Warfarin & 4.0 & $<24$ & C3-5 & C & 0 & No \\
\hline 5 & 64 & M & Yes & No & No & 0.9 & $<24$ & C6-7 & B & 0 & No \\
\hline 6 & 69 & $\mathrm{~F}$ & No & Yes & No & 1.2 & $<24$ & Th3-9 & A & 4 & Yes \\
\hline 7 & 72 & M & No & No & Warfarin & 8.4 & $<24$ & Th4-8 & B & 5 & No \\
\hline 8 & 75 & $\mathrm{~F}$ & Yes & No & No & 1.0 & $24-48$ & L3-4 & C & 3 & No \\
\hline 9 & 76 & M & Yes & No & Warfarin & 4.6 & $>48$ & C4-6 & $\mathrm{D}$ & 1 & No \\
\hline 10 & 85 & $\mathrm{~F}$ & No & No & Warfarin & 2.2 & $<24$ & Th1-4 & A & 5 & Yes \\
\hline \multicolumn{12}{|c|}{$\begin{array}{l}\dagger \text { Myelodysplastic syndrome and thrombocytopenia }\left(19 \times 10^{9}\right) \text {. } \\
\text { M, male; F, female. } \\
\text { *Anabolic steroid abuse, hypertrophic cardiomyopathy, and renal insufficiency. } \\
\dagger \text { Classified as a thoracic hematoma. } \\
\ddagger \text { Myelodysplastic syndrome and thrombocytopenia }(19 \times 109) \text {. }\end{array}$} \\
\hline
\end{tabular}


Time from symptom onset to surgery was less than 24 hours in 6 patients, $24-48$ hours in I patient, and more than 48 hours in 3 patients. Symptoms started with neck and back pain without clear radiculopathy in 9 of Io patients. Only I patient had a clear radiculopathy.

Seven patients had 2-4 involved segments and 3 patients 5 or more. Eight of Io hematomas were laterally or posteriorly located and 2 anteriorly or circumferentially. The distribution of involved segments is shown in Figure 1.

Preoperative functional status is shown in Table 2. Five patients had a preoperative Frankel classification of $\mathrm{A}-\mathrm{B}$ and 5 patients had a classification of $\mathrm{C}-\mathrm{E}$. Five patients recovered well to a Nurick score of $0-2$ and 5 patients had poor outcomes with a Nurick score of $3-5$. Of patients with a poor functional outcome, 3 remained chair bound or bedridden (Nurick score of 5). Table 3 shows the univariate association between preoperative variables and Nurick score. Although no statistically significant associations could be established (because of the small sample size), patients with poor preoperative motor function (Frankel class A-C), a greater number of involved segments, and thoracic hematoma had an extremely high rate of poor neurologic outcome (between $80 \%$ and $100 \%$; see Table 3 ). Six patients were operated on within 24 hours of symptom onset but only 2 of these 6 had a good functional outcome. In contrast, 3 patients admitted more than 48 hours from symptom onset recovered well.

Two patients, aged 70 and 85 years, died 17 and 37 days after the surgery, respectively. Both patients died after hospital discharge with significant postoperative morbidity (Nurick scores of 4 and 5 ).

\section{DISCUSSION}

In this surgical case series of ro patients with SS-EDH, good functional outcome was found in half. Because of the small sample size, we did not seek statistical associations; however, patients with poor preoperative motor function, a greater number of involved segments, and thoracic hematoma had remarkably poor postoperative neurologic outcomes. This suggests that functional recovery depends heavily on preoperative functional status and bleeding characteristics.

SS-EDH is a rare neurosurgical emergency. Consequently, most of the previous studies are case reports. ${ }^{4}$ Even large observational studies are lacking. Our findings that preoperative neurologic status is one of the most important predictive factors of recovery is supported in the literature. In a surgical case series of 30 patients (of whom 5 had SS-EDH), preoperative neurologic status correlated strongly with outcome. ${ }^{9}$ Bakker et al. ${ }^{4}$ found similar results in their meta-analysis of 74I SS-EDH cases. Hematoma size and number of involved segments are other factors we found that correlated with outcome and this is supported by the literature as well. ${ }^{4,9-I I}$ We also found an association between hematoma location and outcome. A possible explanation for this is that the thoracic spinal canal is narrower than the cervical and lumbar spinal canals, making the thoracic spinal cord more susceptible to compression-induced ischemia caused by the hematoma. ${ }^{\mathrm{I2}}$ In our series, there was only I patient with a pure lumbar SS-EDH. For statistical reasons, we grouped this patient with the patients with

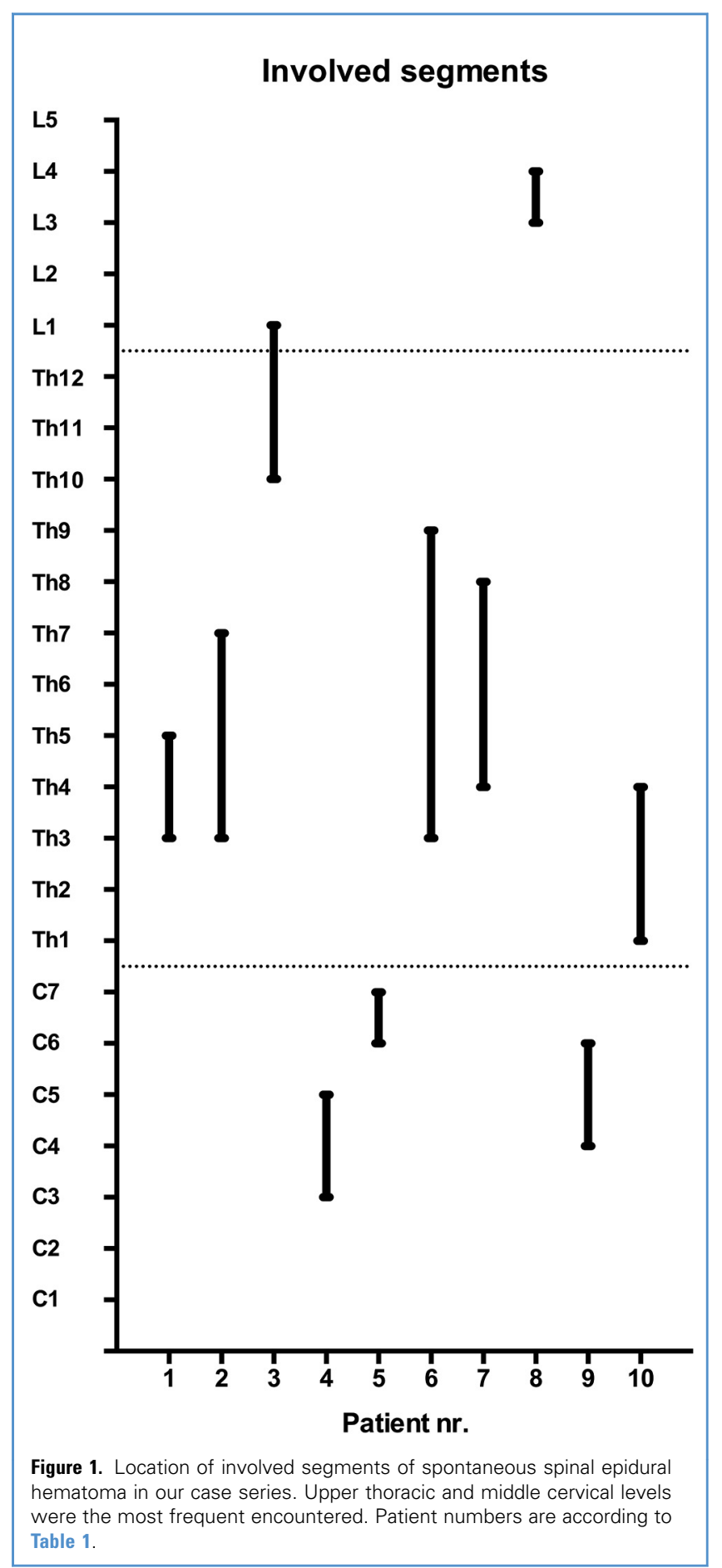

thoracic SS-EDH. Thus, any conclusions regarding outcome for lumbar SS-EDHs cannot be drawn from our series.

Time from symptom onset to hematoma evacuation has been one of the strongest outcome predictors in several studies. ${ }^{9, \mathrm{IO}, \mathrm{I3}, \mathrm{I} 4}$ Foo and Rossier ${ }^{\mathrm{II}}$ found that patients operated on within $\mathrm{I} 2$ hours generally recovered well, whereas patients whose surgery was delayed to $12-36$ hours had a similar outcome to those 
Table 2. Patient Symptoms and Hematoma Characteristics

\begin{tabular}{|c|c|}
\hline Symptom & Number $(\%)$ \\
\hline \multicolumn{2}{|l|}{ Time from symptom onset to surgery } \\
\hline$<24$ hours & $6(60)$ \\
\hline 24-48 hours & $1(10)$ \\
\hline$>48$ hours & $3(30)$ \\
\hline \multicolumn{2}{|l|}{ Pain } \\
\hline Neck/back pain with radiculopathy & $1(10)$ \\
\hline Neck/back pain without radiculopathy & $9(90)$ \\
\hline \multicolumn{2}{|l|}{ Motor dysfunction below lesion } \\
\hline Complete & $5(50)$ \\
\hline Incomplete & $5(50)$ \\
\hline Normal & $0(0)$ \\
\hline \multicolumn{2}{|l|}{ Sensory dysfunction below lesion } \\
\hline Complete & $2(20)$ \\
\hline Incomplete & $6(60)$ \\
\hline Normal & $2(20)$ \\
\hline \multicolumn{2}{|l|}{ Hematoma location, sagittal } \\
\hline Cervical & $3(30)$ \\
\hline Thoracic or lumbar & $6(60)$ \\
\hline Lumbar & $1(10)$ \\
\hline \multicolumn{2}{|l|}{ Hematoma location, axial } \\
\hline Posterior/lateral & $8(80)$ \\
\hline Anterior/circumferential & $2(20)$ \\
\hline \multicolumn{2}{|l|}{ Number of involved segments } \\
\hline $2-4$ segments & $7(70)$ \\
\hline$>4$ segments & $3(30)$ \\
\hline
\end{tabular}

operated on after 36 hours. However, we could not confirm this relationship, possibly because of the small sample size and a type II error. However, in Bakker et al.'s meta-analysis, ${ }^{4}$ operative delay did not predict recovery, suggesting that there might be something else influencing the probability of recovery. For example, Lawton et al. ${ }^{9}$ showed that even patients with a preoperative Frankel grade A (complete motor loss) may recover well. The probability of recovery is highly related to the extent of spinal cord ischemia, which in turn is determined by the force, duration, and rate of compression exerted by the hematoma. ${ }^{15-2 I}$ SS-EDHs are, in general, venous bleedings from the posterior internal vertebral venous plexus. ${ }^{3,6}$ Venous bleedings may be more insidious than arterial bleedings because they bleed less profusely and slow symptom development. This is a major cause of primary misdiagnosis delaying operative care. We believe that it is plausible that in patients with a more rapid onset of symptoms, appropriate diagnostic measures are performed at an earlier stage, leading to shorter operative intervals. Patients with longer operative delays may also have a slower developing hematoma with decreased force and rate of compression but increased duration. There is probably a
Table 3. Univariate Analysis of Outcome Predictors

\begin{tabular}{|c|c|c|c|}
\hline & $\begin{array}{l}\text { Good Outcome } \\
\quad(n=5)\end{array}$ & $\begin{array}{l}\text { Poor outcome } \\
\quad(n=5)\end{array}$ & $P$ Value \\
\hline Age (years), median (IQR) & $63(53-70)$ & $72(66-80)$ & 0.151 \\
\hline $\begin{array}{l}\text { International normalized } \\
\text { ratio, median (IOR) }\end{array}$ & $3.5(1.7-4.3)$ & $1.2(1-0-5.3)$ & 0.548 \\
\hline \multicolumn{4}{|c|}{ Time from symptom onset to surgery } \\
\hline$<24$ hours & $2(40)$ & $4(80)$ & 0.167 \\
\hline 24-48 hours & $0(0)$ & $1(20)$ & \\
\hline$>48$ hours & $3(60)$ & $0(0)$ & \\
\hline \multicolumn{4}{|c|}{ Motor dysfunction below lesion } \\
\hline Complete & $1(20)$ & $4(80)$ & 0.206 \\
\hline Incomplete & $4(80)$ & $1(20)$ & \\
\hline \multicolumn{4}{|c|}{ Number of involved segments } \\
\hline $2-4$ & $4(80)$ & $1(20)$ & 0.206 \\
\hline$>4$ & $1(20)$ & $4(80)$ & \\
\hline \multicolumn{4}{|l|}{ Location } \\
\hline Cervical & $3(60)$ & $0(0)$ & 0.167 \\
\hline Thoracic & $2(40)$ & $4(80)$ & \\
\hline Lumbar & $0(0)$ & $1(20)$ & \\
\hline Frankel class & & & 0.999 \\
\hline$A-C$ (poor) & $1(20)$ & $5(100)$ & \\
\hline D-E (good) & $4(80)$ & $0(0)$ & \\
\hline \multicolumn{4}{|c|}{$\begin{array}{l}\text { Values are number (\%) unless otherwise stated. Fisher exact test used for categorical } \\
\text { variables. Good outcome is defined as a Nurick score of } 0 \text { (signs and symptoms of root } \\
\text { involvement but without evidence of spinal cord disease), } 1 \text { (signs of spinal cord } \\
\text { disease but no difficulty walking), } 2 \text { (slight difficulty walking that does not prevent full- } \\
\text { time employment). Poor outcome is defined as a Nurick score of } 3 \text { (extreme difficulty } \\
\text { in walking that requires assistance and prevents full-time employment and occupa- } \\
\text { tion), } 4 \text { (able to walk only with someone else's help or with the aid of a walker), or } 5 \\
\text { (chair bound or bedridden). }\end{array}$} \\
\hline
\end{tabular}

complex relationship between force, duration, and rate of compression that we still do not understand, which is why some patients with long operative intervals recover and other do not. Tarlov et al. ${ }^{\mathrm{I}-2 \mathrm{I}}$ suggested that the time from symptom onset to maximal neurologic deficit estimates the rate of cord compression. Duration would then be estimated as the time from maximal neurologic deficit to surgical intervention. Still, estimating the force of compression in the clinical setting remains a challenge and an impediment to outcome prediction.

Patients in our case series were notably older than previously reported. Mean patient age in our study was 70 years, whereas it was 52 years in the meta-analysis by Bakker et al. ${ }^{4}$ This indicates some case-mix differences between our study and previous studies. In the study by Bakker et al., there were no significant differences in age between patients with good and poor neurologic outcomes. However, the absolute age difference between those with good and poor outcome was 2 years ( 57 vs. 59 years), whereas it was 9 years ( 63 vs. 72 years) in our study. However, age was not a 
significant predictor of outcome in our study, which of course might be the result of the limited number of patients. Thus, the effect of age on outcome after SS-EDH remains controversial and warrants further studies.

Acute local neck and back pain with progressive hemiparesis or tetraparesis should promptly warrant further investigation to exclude the possibility of SS-EDH. Magnetic resonance imaging of the spinal cord is the gold standard for diagnosing SS-EDH. Patients on oral anticoagulants should promptly have their coagulation status restored to minimize progression of the hematoma. Experience of how to treat patients on new oral anticoagulants is still lacking and needs to be addressed.

Investigating SS-EDH remains challenging because of the nature and rarity of SS-EDH. Multicenter prospectively collected data seem necessary to understand this rare but devastating disease.

Limitations

There are some limitations to our study that deserve mentioning. First, this was a retrospective single-center surgical case series, which made our patient sample small and increased the likelihood of type II errors. Second, because of the retrospective nature of the study, we were not able to precisely assess time from symptom onset to maximal neurologic deficit and time from maximal neurologic deficit to operative intervention. Thus, we used the time from symptom onset to operation as our measure of time. We were unable to investigate the natural history of the SS-EDH because we did not include patients treated conservatively because this group are seldom admitted to our center.

\section{CONCLUSIONS}

SS-EDH remains a major challenging neurosurgical emergency associated with severe comorbidities. In our series, half of the patients recovered well. Although no statistically significant association could be established, hematoma location and size and preoperative motor function seem to be the major predictive factors. We could not establish any relationship between operative delay and outcome.

\section{REFERENCES}

I. Holtås S, Heiling M, Lönntoft M. Spontaneous spinal epidural hematoma: findings at MR imaging and clinical correlation. Radiology. I996;199: 409-4I3.

2. Akimoto T, Yamada T, Shinoda S, Asano Y, Nagata D. Spontaneous spinal epidural hematoma as a potentially important stroke mimic. J Cent Nerv Syst Dis. 20I4;6:15-20.

3. Groen RJ, Ponssen H. The spontaneous spinal epidural hematoma. A study of the etiology. J Neurol Sci. I990;98:I2I-I38.

4. Bakker NA, Veeger NJ, Vergeer RA, Groen RJM. Prognosis after spinal cord and cauda compression in spontaneous spinal epidural hematomas. Neurology. 2015;84:I894-I903.

5. Groen RJ, Grobbelaar M, Muller CJ, van Solinge G, Verhoof O, du Toit DF, et al, Morphology of the human internal vertebral venous plexus: a cadaver study after latex injection in the 2I-25-week fetus. Clin Anat. 2005;I8:397-403.

6. Groen RJ, Groenewegen HJ, van Alphen HA, Hoogland PV. Morphology of the human internal vertebral venous plexus: a cadaver study after intravenous Araldite CY 22I injection. Anat Rec. I997;249:285-294.

7. Nurick S. The pathogenesis of the spinal cord disorder associated with cervical spondylosis. Brain. I972;95:87-I00.

8. Ditunno JF, Young W, Donovan WH, Creasey G. The international standards booklet for neurological and functional classification of spinal cord injury. American Spinal Injury Association. Paraplegia. I994;32:70-80.

9. Lawton MT, Porter RW, Heiserman JE, Jacobowitz R, Sonntag VK, Dickman CA. Surgical management of spinal epidural hematoma: relationship between surgical timing and neurological outcome. J Neurosurg. I995;83:I-7

ro. Hussenbocus SM, Wilby MJ, Cain C, Hall D Spontaneous spinal epidural hematoma: a case report and literature review. J Emerg Med. 20I2;42: езг-ез4.

II. Foo D, Rossier AB. Preoperative neurological status in predicting surgical outcome of spinal epidural hematomas. Surg Neurol. I98I;I5:389-40I.

I2. Lazorthes G, Gouaze A, Zadeh JO, Santini J , Lazorthes Y, Burdin P. Arterial vascularization of the spinal cord. Recent studies of the anastomotic substitution pathways. J Neurosurg. I971;35:253-262.

I3. Mukerji N, Todd N. Spinal epidural haematoma; factors influencing outcome. $\mathrm{Br}$ J Neurosurg. 20I3; 27:712-717.

I4. Hejazi N, Thaper PY, Hassler W. Nine cases of nontraumatic spinal epidural hematoma. Neurol Med Chir (Tokyo). I998;38:718-723.

I5. Dolan EJ, Transfeldt EE, Tator $\mathrm{CH}$, Simmons $\mathrm{EH}$, Hughes KF. The effect of spinal distraction on regional spinal cord blood flow in cats. J Neurosurg. I980;53:756-764.

I6. Dolan EJ, Tator $\mathrm{CH}$, Endrenyi L. The value of decompression for acute experimental spinal cord compression injury. J Neurosurg. I980;53:749-755.
I7. Tarlov IM. Acute spinal cord compression paralysis. J Neurosurg. I972;36:10-20.

I8. Tarlov IM, Klinger H, Vitale S. Spinal cord compression studies. I. Experimental techniques to produce acute and gradual compression. AMA Arch Neurol Psychiatry. I953;70:813-8Ig.

I9. Tarlov IM, Klinger H. Spinal cord compression studies. II. Time limits for recovery after acute compression in dogs. AMA Arch Neurol Psychiatry. I954;7I:27I-290.

20. Tarlov IM. Spinal cord compression studies. III Time limits for recovery after gradual compression in dogs. AMA Arch Neurol Psychiatry. I954;71:588-597.

2I. Tarlov IM, HERZ E. Spinal cord compression studies. IV. Outlook with complete paralysis in man. AMA Arch Neurol Psychiatry. I954;72:43-59.

Conflict of interest statement: R.R. has received personal research grants from Svenska Kulturfonden, the Emil Aaltonen Foundation, the Maire Taponen Foundation and Medicinska Understödsföreningen Liv \& Hälsa.

Received 18 April 2016; accepted 23 May 2016

Citation: World Neurosurg. (2016) 93:55-59.

http://dx.doi.org/10.1016/j.wneu.2016.05.072

Journal homepage: www.WORLDNEUROSURGERY.org

Available online: www.sciencedirect.com

1878-8750/\$ - see front matter (C) 2016 Elsevier Inc. All rights reserved. 